\title{
Attractive points and convergence theorems of generalized hybrid mapping
}

\author{
Yuchun Zheng* \\ School of Mathematics and Information Science, Henan Normal University, XinXiang, P.R. China, 453007
}

\begin{abstract}
In this paper, by means of the concept of attractive points of a nonlinear mapping, we prove strong convergence theorem of the Ishikawa iteration for an $(\alpha, \beta)$-generalized hybrid mapping in a uniformly convex Banach space, and obtain weak convergence theorem of the Ishikawa iteration for such a mapping in a Hilbert space.
\end{abstract}

Keywords: Attractive points, generalized hybrid mapping, Ishikawa iteration, Mann iteration, Xu's inequality.

2010 MSC: 47H10, 54H25, 49J40, 47H05, 47H04, 65J15, 47H10.

\section{Introduction}

Let $E$ be a Banach space with the norm $\|\cdot\|$ and let $K$ be a nonempty subset of $E$. In 2010, Kocourek, Takahashi and Yao [5] firstly introduced the concept of the generalized hybrid mapping, which contains the classes of nonexpansive mappings, nonspreading mappings, and hybrid mappings. A mapping $T: K \rightarrow K$ is called $(\alpha, \beta)$-generalized hybrid if there exist $\alpha, \beta \in \mathbb{R}$ such that

$$
\alpha\|T x-T y\|^{2}+(1-\alpha)\|x-T y\|^{2} \leq \beta\|T x-y\|^{2}+(1-\beta)\|x-y\|^{2}
$$

for all $x, y \in K$, where $\mathbb{R}$ is the set of real numbers. $T$ is said to be nonexpansive if $T$ is $(1,0)$-generalized hybrid; $T$ is called hybrid (Takahashi [10]) if $T$ is $\left(\frac{3}{2}, \frac{1}{2}\right)$-generalized hybrid, i.e.

$$
3\|T x-T y\|^{2} \leq\|x-T y\|^{2}+\|T x-y\|^{2}+\|x-y\|^{2} \quad \forall x, y \in K ;
$$

$T$ is called nonspreading (Kohsaka and Takahashi [6]) if $T$ is $(2,1)$-generalized hybrid, i.e.

$$
2\|T x-T y\|^{2} \leq\|x-T y\|^{2}+\|T x-y\|^{2} \quad \forall x, y \in K .
$$

\footnotetext{
*Corresponding author

Email address: zhengyuchun1@yeah.net (Yuchun Zheng)
} 
Baillon [1] proved the first nonlinear ergodic theorem: suppose that $K$ is a nonempty closed convex subset of Hilbert space $E$ and $T: K \rightarrow K$ is nonexpansive mapping such that $F(T) \neq \emptyset$, then $\forall x \in K$, the Cesàro means

$$
T_{n} x=\frac{1}{n+1} \sum_{i=0}^{n} T^{i} x
$$

weakly converges to a fixed point of $T$.

Bruck [2, 3] studied the property of Cesàro means for nonexpansive mapping in uniformly convex Banach space. Takahashi and Yao [11 proved the nonlinear ergodic theorem for both hybrid and nonspreading mappings in a Hilbert space. Kocourek, Takahashi and Yao [5] showed that both the nonlinear ergodic theorem and the weak convergence theorem of the Mann iteration for $(\alpha, \beta)$-generalized hybrid mapping. The Mann iteration is the original definition of Mann [7] for a nonexpansive mapping $T$,

$$
x_{n+1}=\alpha_{n} x_{n}+\left(1-\alpha_{n}\right) T x_{n} \quad\left\{\alpha_{n}\right\} \subset(0,1), x_{1} \in K .
$$

Takahashi and Takeuchi [12] obtained the nonlinear ergodic theorem without convexity for $(\alpha, \beta)$-generalized hybrid mappings. Hojo and Takahashi [4] showed the strong convergence of the Halpern iteration of Cesàro means for $(\alpha, \beta)$-generalized hybrid mapping $T$ under some proper conditions,

$$
x_{n+1}=\alpha_{n} u+\left(1-\alpha_{n}\right) \frac{1}{n+1} \sum_{i=0}^{n} T^{i} x_{n} \quad\left\{\alpha_{n}\right\} \subset(0,1), u, x_{1} \in K .
$$

In this paper, we will deal with strong and weak convergence of the Ishikawa iteration for finding attractive points of $(\alpha, \beta)$-generalized hybrid mappings under some conditions on the sequences $\left\{\alpha_{n}\right\}$ and $\left\{\beta_{n}\right\}$ in $(0,1)$,

$$
\begin{cases}x_{n+1} & =\alpha_{n} x_{n}+\left(1-\alpha_{n}\right) T y_{n} \\ y_{n} & =\beta_{n} x_{n}+\left(1-\beta_{n}\right) T x_{n}\end{cases}
$$

Our results obviously develop and complement the corresponding ones of Kocourek, Takahashi and Yao [5], Takahashi and Yao [11], Takahashi and Takeuchi [12, Takahashi [10] and others.

\section{Preliminaries and basic results}

Let $\mathbb{N}$ and $\mathbb{R}$ be the sets of positive integers and real numbers, respectively. Let $K$ be a nonempty subset of a Banach space $E$ with the norm $\|\cdot\|$ and let $T$ be a mapping $T$ from $K$ to $E$. A point $y \in E$ is called an attractive point of $T$ if for all $x \in K$

$$
\|T x-y\| \leq\|x-y\| .
$$

We denote by $A(T)$ the set of all attractive points of $T$, i.e.,

$$
A(T)=\{y \in E ;\|T x-y\| \leq\|x-y\| \quad \forall x \in K\} .
$$

Takahashi and Takeuchi [12] used this concept and proved the closed and convex property of $A(T)$ in a Hilbert space $H$. For more details, see Takahashi and Takeuchi [12].

A Banach space $E$ is said to be uniformly convex if for all

$$
\begin{gathered}
\varepsilon \in[0,2], \\
\exists \delta_{\varepsilon}>0
\end{gathered}
$$

such that

$$
\|x\|=\|y\|=1 \text { implies } \frac{\|x+y\|}{2}<1-\delta_{\varepsilon} \text { whenever }\|x-y\| \geq \varepsilon .
$$

The following lemmas are well-known which can be found in [13]. 
Lemma 2.1. (Xu [13, Theorem 2]) Let $q>1$ and $r>0$ be two fixed real numbers. Then a Banach space is uniformly convex if and only if there exists a continuous strictly increasing convex function $g:[0,+\infty) \rightarrow$ $[0,+\infty)$ with $g(0)=0$ such that

$$
\|\lambda x+(1-\lambda) y\|^{q} \leq \lambda\|x\|^{q}+(1-\lambda)\|y\|^{q}-\omega_{q}(\lambda) g(\|x-y\|),
$$

for all $x, y \in B_{r}(0)=\{x \in E ;\|x\| \leq r\}$ and $\lambda \in[0,1]$, where $\omega_{q}(\lambda)=\lambda^{q}(1-\lambda)+\lambda(1-\lambda)^{q}$.

Note that the inequality in Lemma 2.1 is known as Xu's inequality.

Let $H$ be a real Hilbert space with the norm $\|\cdot\|$ and the inner produce $\langle\cdot, \cdot\rangle$. Obviously, the Xu's inequality is replaced by the following equality in a Hilbert space $H$, for $x, y \in H$ and $t \in \mathbb{R}$,

$$
\|t x+(1-t) y\|^{2}=t\|x\|^{2}+(1-t)\|y\|^{2}-t(1-t)\|x-y\|^{2} .
$$

Lemma 2.2. Let $K$ be a nonempty closed and convex subset of a real uniformly convex Banach space $E$ and let $T: K \rightarrow K$ be a $(\alpha, \beta)$-generalized hybrid mapping with $A(T) \neq \emptyset$. Suppose that the sequence $\left\{x_{n}\right\}$ is defined by the Ishikawa iteration

$$
\begin{cases}x_{n+1} & =\alpha_{n} x_{n}+\left(1-\alpha_{n}\right) T y_{n} \\ y_{n} & =\beta_{n} x_{n}+\left(1-\beta_{n}\right) T x_{n}\end{cases}
$$

where the sequences $\left\{\alpha_{n}\right\}$ and $\left\{\beta_{n}\right\}$ in $(0,1)$ such that

$$
\liminf _{n \rightarrow \infty} \beta_{n}\left(1-\alpha_{n}\right)\left(1-\beta_{n}\right)>0 .
$$

Then (i) the sequence $\left\{x_{n}\right\}$ is bounded;

(ii) the limit $\lim _{n \rightarrow \infty}\left\|x_{n}-u\right\|$ exists for each $u \in A(T)$;

(iii) $\lim _{n \rightarrow \infty}\left\|x_{n}-T x_{n}\right\|=0$.

Proof. Take $u \in A(T)$.

By the definition of the attractive point, we have

$$
\begin{aligned}
\left\|x_{n+1}-u\right\| & =\left\|\alpha_{n}\left(x_{n}-u\right)+\left(1-\alpha_{n}\right)\left(T y_{n}-u\right)\right\| \\
& \leq \alpha_{n}\left\|x_{n}-u\right\|+\left(1-\alpha_{n}\right)\left\|T y_{n}-u\right\| \\
& \leq \alpha_{n}\left\|x_{n}-u\right\|+\left(1-\alpha_{n}\right)\left\|y_{n}-u\right\| \\
& \leq \alpha_{n}\left\|x_{n}-u\right\|+\left(1-\alpha_{n}\right)\left(\beta_{n}\left\|x_{n}-u\right\|+\left(1-\beta_{n}\right)\left\|T x_{n}-u\right\|\right) \\
& \leq\left(\alpha_{n}+\left(1-\alpha_{n}\right)\left(\beta_{n}+\left(1-\beta_{n}\right)\right)\right)\left\|x_{n}-u\right\| \\
& \leq\left\|x_{n}-u\right\| \\
& \quad \vdots \\
& \leq\left\|x_{1}-u\right\| .
\end{aligned}
$$

So the sequence $\left\{x_{n}\right\}$ is bounded and the sequence $\left\{\left\|x_{n}-u\right\|\right\}$ is monotone non-increasing, and hence the limit $\lim _{n \rightarrow \infty}\left\|x_{n}-u\right\|$ exists for each $u \in A(T)$.

Now we show (iii).

Let

$$
r \geq \max _{n \in \mathbb{N}}\left\|x_{n}-u\right\|
$$

Then

$$
\left\|T y_{n}-u\right\| \leq\left\|y_{n}-u\right\| \leq\left\|x_{n}-u\right\| \leq r \text { and }\left\|T x_{n}-u\right\| \leq\left\|x_{n}-u\right\| \leq r .
$$


It follows from Lemma $2.1(q=2)$ that

$$
\begin{gathered}
\left\|x_{n+1}-u\right\|^{2} \\
\leq \alpha_{n}\left(x_{n}-u\right)+\left(1-\alpha_{n}\right)\left(T y_{n}-u\right) \|^{2} \\
\leq \alpha_{n}\left\|x_{n}-u\right\|^{2}+\left(1-\alpha_{n}\right)\left\|T y_{n}-u\right\|^{2} \\
\leq \alpha_{n}\left\|x_{n}-u\right\|^{2}+\left(1-\alpha_{n}\right)\left\|y_{n}-u\right\|^{2} \\
=\alpha_{n}\left\|x_{n}-u\right\|^{2}+\left(1-\alpha_{n}\right)\left\|\beta_{n}\left(x_{n}-u\right)+\left(1-\beta_{n}\right)\left(T x_{n}-u\right)\right\|^{2} \\
\leq \alpha_{n}\left\|x_{n}-u\right\|^{2}+\left(1-\alpha_{n}\right)\left(\beta_{n}\left\|x_{n}-u\right\|^{2}+\left(1-\beta_{n}\right)\left\|T x_{n}-u\right\|^{2}\right. \\
\left.-\beta_{n}\left(1-\beta_{n}\right) g\left(\left\|T x_{n}-x_{n}\right\|\right)\right) \\
\leq \alpha_{n}\left\|x_{n}-u\right\|^{2}+\left(1-\alpha_{n}\right)\left(\beta_{n}\left\|x_{n}-u\right\|^{2}+\left(1-\beta_{n}\right)\left\|x_{n}-u\right\|^{2}\right. \\
\left.-\beta_{n}\left(1-\beta_{n}\right) g\left(\left\|T x_{n}-x_{n}\right\|\right)\right) \\
\leq\left\|x_{n}-u\right\|^{2}-\left(1-\alpha_{n}\right) \beta_{n}\left(1-\beta_{n}\right) g\left(\left\|T x_{n}-x_{n}\right\|\right) .
\end{gathered}
$$

Then we have

$$
\left(1-\alpha_{n}\right) \beta_{n}\left(1-\beta_{n}\right) g\left(\left\|T x_{n}-x_{n}\right\|\right) \leq\left\|x_{n}-u\right\|^{2}-\left\|x_{n+1}-u\right\|^{2},
$$

and so,

$$
\sum_{n=1}^{\infty}\left(1-\alpha_{n}\right) \beta_{n}\left(1-\beta_{n}\right) g\left(\left\|T x_{n}-x_{n}\right\|\right) \leq\left\|x_{1}-u\right\|^{2}<+\infty .
$$

From the condition $(2.4)$, it follows that

$$
\lim _{n \rightarrow \infty} g\left(\left\|T x_{n}-x_{n}\right\|\right)=0 .
$$

By the property of the function $g$, we have

$$
\lim _{n \rightarrow \infty}\left\|T x_{n}-x_{n}\right\|=0 .
$$

This completes the proof.

When $\alpha_{n}=0$ for all $n$, the following conclusions hold obviously.

Corollary 2.3. Let $K$ be a nonempty closed and convex subset of a real uniformly convex Banach space $E$ and let $T: K \rightarrow K$ be a $(\alpha, \beta)$-generalized hybrid mapping with $A(T) \neq \emptyset$. Suppose that the sequence $\left\{x_{n}\right\}$ is defined by the following iteration

$$
x_{n+1}=T\left(\beta_{n} x_{n}+\left(1-\beta_{n}\right) T x_{n}\right)
$$

where the sequence $\left\{\beta_{n}\right\}$ in $(0,1)$ such that

$$
\liminf _{n \rightarrow \infty} \beta_{n}\left(1-\beta_{n}\right)>0
$$

Then (i) the sequence $\left\{x_{n}\right\}$ is bounded;

(ii) the limit $\lim _{n \rightarrow \infty}\left\|x_{n}-u\right\|$ exists for each $u \in A(T)$;

(iii) $\lim _{n \rightarrow \infty}\left\|x_{n}-T x_{n}\right\|=0$.

\section{Strongly Convergent Theorems}

Let $K$ be a nonempty subset of a Banach space $E$. A mapping $T: K \rightarrow K$ is said to satisfy Condition $I$ if there is a nondecreasing function $f:[0, \infty) \rightarrow[0, \infty)$ with $f(0)=0, f(r)>0$ for $r \in(0, \infty)$ such that

$$
\|x-T x\| \geq f(d(x, A(T))) \text { for all } x \in K,
$$

where $d(x, A(T))=\inf \{\|x-y\| ; y \in A(T)\}$. This concept was introduced by Senter and Dotson [9] and the examples of mappings that satisfy Condition I was given. 
Theorem 3.1. Let $K$ be a nonempty closed and convex subset of a uniformly convex Banach space $E$ and and let $T: K \rightarrow K$ be a $(\alpha, \beta)$-generalized hybrid mapping with $A(T) \neq \emptyset$ and satisfying Condition $I$. Suppose that the sequence $\left\{x_{n}\right\}$ is defined by the Ishikawa iteration

$$
\begin{cases}x_{n+1} & =\alpha_{n} x_{n}+\left(1-\alpha_{n}\right) T y_{n} \\ y_{n} & =\beta_{n} x_{n}+\left(1-\beta_{n}\right) T x_{n}\end{cases}
$$

where the sequences $\left\{\alpha_{n}\right\}$ and $\left\{\beta_{n}\right\}$ in $(0,1)$ such that

$$
\liminf _{n \rightarrow \infty} \beta_{n}\left(1-\alpha_{n}\right)\left(1-\beta_{n}\right)>0 .
$$

Then the sequence $\left\{x_{n}\right\}$ converges strongly to an attractive point $z$ of $T$.

Proof. It follows from Lemma 2.2 that the sequence $\left\{x_{n}\right\}$ is bounded and

$$
\left\|x_{n+1}-u\right\| \leq\left\|x_{n}-u\right\| \text { for each } u \in A(T) \text { and } \lim _{n \rightarrow \infty}\left\|x_{n}-T x_{n}\right\|=0 .
$$

Then Condition I implies $\lim _{n \rightarrow \infty} f\left(d\left(x_{n}, A(T)\right)\right)=0$, and hence

$$
\lim _{n \rightarrow \infty} d\left(x_{n}, A(T)\right)=0 .
$$

Next we show that the sequence $\left\{x_{n}\right\}$ is a Cauchy sequence of $E$. In fact, for any $n, m \in \mathbb{N}$, without loss of generality, we may set $m>n$, then $\left\|x_{m}-u\right\| \leq\left\|x_{n}-u\right\|$ for each $u \in A(T)$ by $([3.3)$ ), and so

$$
\left\|x_{n}-x_{m}\right\| \leq\left\|x_{n}-u\right\|+\left\|u-x_{m}\right\| \leq 2\left\|x_{n}-u\right\| .
$$

Since $u$ is arbitrary, then we may take the infimum for $u$ in $((3.5))$,

$$
\left\|x_{n}-x_{m}\right\| \leq 2 \inf \left\{\left\|x_{n}-u\right\| ; u \in A(T)\right\}=2 d\left(x_{n}, A(T)\right) .
$$

From $\left([3.4)\right.$, it follows that as $\lim _{n \rightarrow \infty}\left\|x_{n}-x_{m}\right\|=0$, which means that $\left\{x_{n}\right\}$ is a Cauchy sequence. So there exists $z \in E$ such that

$$
\lim _{n \rightarrow \infty}\left\|x_{n}-z\right\|=0
$$

By $((3.3))$, we have

$$
\lim _{n \rightarrow \infty}\left\|T x_{n}-z\right\|=0 .
$$

Now we prove $z \in A(T)$. In fact, it follows from the definition of $(\alpha, \beta)$-generalized hybrid mapping that for all $x \in K$,

$$
\alpha\left\|T x_{n}-T x\right\|^{2}+(1-\alpha)\left\|x_{n}-T x\right\|^{2} \leq \beta\left\|T x_{n}-x\right\|^{2}+(1-\beta)\left\|x_{n}-x\right\|^{2} .
$$

Let $n \rightarrow \infty$ in $(\underline{3.6})$. Then by the continuity of the norm $\|\cdot\|$ and the function $g(t)=t^{2}$, we have

$$
\alpha\|z-T x\|^{2}+(1-\alpha)\|z-T x\|^{2} \leq \beta\|z-x\|^{2}+(1-\beta)\|z-x\|^{2},
$$

and hence

$$
\|z-T x\| \leq\|z-x\| \text { for all } x \in K .
$$

So $z \in A(T)$ and $\lim _{n \rightarrow \infty}\left\|x_{n}-z\right\|=0$. The proof is completed.

A mapping $T: K \rightarrow E$ is said to be demicompact (Petryshyn [8]) provided whenever a sequence $\left\{x_{n}\right\} \subset K$ is bounded and the sequence $\left\{x_{n}-T x_{n}\right\}$ strongly converges, then there is a subsequence $\left\{x_{n_{k}}\right\}$ which strongly converges. 
Theorem 3.2. Let $K$ be a nonempty closed and convex subset of a uniformly convex Banach space $E$ and and let $T: K \rightarrow K$ be $(\alpha, \beta)$-generalized hybrid and demicompact with $A(T) \neq \emptyset$. Suppose that the sequence $\left\{x_{n}\right\}$ is defined by the Ishikawa iteration ((3.1)) and the sequences $\left\{\alpha_{n}\right\}$ and $\left\{\beta_{n}\right\}$ satisfy ((3.2)). Then the sequence $\left\{x_{n}\right\}$ converges strongly to an attractive point $z$ of $T$.

Proof. It follows from Lemma 2.2 that the sequence $\left\{x_{n}\right\}$ is bounded and

$$
\lim _{n \rightarrow \infty}\left\|x_{n}-T x_{n}\right\|=0 .
$$

Then the demicompactness of $T$ implies there is a subsequence $\left\{x_{n_{k}}\right\} \subset\left\{x_{n}\right\}$ and $z \in E$ such that

$$
\lim _{k \rightarrow \infty}\left\|x_{n_{k}}-z\right\|=0
$$

By $([3.7))$, we also have

$$
\lim _{k \rightarrow \infty}\left\|T x_{n_{k}}-z\right\|=0 .
$$

From the definition of $(\alpha, \beta)$-generalized hybrid mapping, it follows that for all $x \in K$,

$$
\alpha\left\|T x_{n_{k}}-T x\right\|^{2}+(1-\alpha)\left\|x_{n_{k}}-T x\right\|^{2} \leq \beta\left\|T x_{n_{k}}-x\right\|^{2}+(1-\beta)\left\|x_{n_{k}}-x\right\|^{2} .
$$

Let $k \rightarrow \infty$ in $(\sqrt{3.9})$ ). Then by the continuity of the norm $\|\cdot\|$ and the function $g(t)=t^{2}$, we have

$$
\|z-T x\| \leq\|z-x\| \text { for all } x \in K .
$$

So $z \in A(T)$. Since $\lim _{n \rightarrow \infty}\left\|x_{n}-u\right\|$ exists for each $u \in A(T)$ by Lemma 2.2 (ii), then we have

$$
\lim _{n \rightarrow \infty}\left\|x_{n}-z\right\|=0
$$

The proof is completed.

The condition 3.2 contains $\alpha_{n} \equiv 0$ and $\liminf _{n \rightarrow \infty} \beta_{n}\left(1-\beta_{n}\right)>0$ as special cases. So the following result is obtained easily.

Corollary 3.3. Let $K$ be a nonempty closed and convex subset of a real uniformly convex Banach space $E$ and let $T: K \rightarrow K$ be a $(\alpha, \beta)$-generalized hybrid mapping with $A(T) \neq \emptyset$. Suppose that the sequence $\left\{x_{n}\right\}$ is defined by the following iteration

$$
x_{n+1}=T\left(\beta_{n} x_{n}+\left(1-\beta_{n}\right) T x_{n}\right)
$$

where the sequence $\left\{\beta_{n}\right\}$ in $(0,1)$ such that

$$
\liminf _{n \rightarrow \infty} \beta_{n}\left(1-\beta_{n}\right)>0
$$

Assume that $T$ either satisfies Condition I or is demicompact. Then the sequence $\left\{x_{n}\right\}$ converges strongly to an attractive point $z$ of $T$.

\section{Weakly Convergent Theorems}

Let $\left\{x_{n}\right\}$ is a sequence in $E$, then $x_{n} \rightarrow x$ will denote weak convergence of the sequence $\left\{x_{n}\right\}$ to $x$. 
Theorem 4.1. Let $K$ be a nonempty closed and convex subset of a Hilbert space $H$ and let $T: K \rightarrow K$ be a $(\alpha, \beta)$-generalized hybrid mapping with $A(T) \neq \emptyset$. Suppose that the sequence $\left\{x_{n}\right\}$ is defined by the Ishikawa iteration

$$
\left\{\begin{array}{ll}
x_{n+1} & =\alpha_{n} x_{n}+\left(1-\alpha_{n}\right) T y_{n} \\
y_{n} & =\beta_{n} x_{n}+\left(1-\beta_{n}\right) T x_{n}
\end{array},\right.
$$

where the sequences $\left\{\alpha_{n}\right\}$ and $\left\{\beta_{n}\right\}$ in $(0,1)$ such that

$$
\liminf _{n \rightarrow \infty} \beta_{n}\left(1-\alpha_{n}\right)\left(1-\beta_{n}\right)>0 .
$$

Then the sequence $\left\{x_{n}\right\}$ converges weakly to an attractive point $z$ of $T$.

Proof. It follows from Lemma 2.2 that the sequence $\left\{x_{n}\right\}$ is bounded and

$$
\lim _{n \rightarrow \infty}\left\|x_{n}-u\right\| \text { exists for each } u \in A(T) \text { and } \lim _{n \rightarrow \infty}\left\|x_{n}-T x_{n}\right\|=0 .
$$

Then there exists a subsequence $\left\{x_{n_{k}}\right\}$ of $\left\{x_{n}\right\}$ and $z \in H$ such that $x_{n_{k}} \rightarrow z$. We claim $z \in A(T)$. In fact, it follows from the definition of $(\alpha, \beta)$-generalized hybrid mapping that for all $x \in K$,

$$
\alpha\left\|T x_{n_{k}}-T x\right\|^{2}+(1-\alpha)\left\|x_{n_{k}}-T x\right\|^{2} \leq \beta\left\|T x_{n_{k}}-x\right\|^{2}+(1-\beta)\left\|x_{n_{k}}-x\right\|^{2} .
$$

Then we have

$$
\begin{aligned}
& \alpha\left(\left\|x_{n_{k}}-T x\right\|^{2}+2\left\langle x_{n_{k}}-T x, T x_{n_{k}}-x_{n_{k}}\right\rangle+\left\|T x_{n_{k}}-x_{n_{k}}\right\|^{2}\right)+(1-\alpha)\left\|x_{n_{k}}-T x\right\|^{2} \\
& =\alpha\left\|T x_{n_{k}}-T x\right\|^{2}+(1-\alpha)\left\|x_{n_{k}}-T x\right\|^{2} \\
& \leq \beta\left\|T x_{n_{k}}-x\right\|^{2}+(1-\beta)\left\|x_{n_{k}}-x\right\|^{2} \\
& \leq \beta\left(\left\|T x_{n_{k}}-x_{n_{k}}\right\|^{2}+2\left\langle T x_{n_{k}}-x_{n_{k}}, x_{n_{k}}-x\right\rangle+\left\|x_{n_{k}}-x\right\|^{2}\right)+(1-\beta)\left\|x_{n_{k}}-x\right\|^{2} .
\end{aligned}
$$

Let $k \rightarrow \infty$. Then by $(4.3))\left(\lim _{k \rightarrow \infty}\left\|x_{n_{k}}-T x_{n_{k}}\right\|=0\right)$, we have

$$
\limsup _{k \rightarrow \infty}\left\|x_{n_{k}}-T x\right\|^{2} \leq \limsup _{k \rightarrow \infty}\left\|x_{n_{k}}-x\right\|^{2} .
$$

Since $x_{n_{k}} \rightarrow z$ and

$$
\left\|x_{n_{k}}-x\right\|^{2}=\left\|x_{n_{k}}-T x\right\|^{2}+2\left\langle x_{n_{k}}-T x, T x-x\right\rangle+\|T x-x\|^{2},
$$

then

$$
\limsup _{k \rightarrow \infty}\left\|x_{n_{k}}-x\right\|^{2}=\limsup _{k \rightarrow \infty}\left\|x_{n_{k}}-T x\right\|^{2}+2\langle z-T x, T x-x\rangle+\|T x-x\|^{2} .
$$

Since $\|z-x\|^{2}=\|z-T x\|^{2}+2\langle z-T x, T x-x\rangle+\|T x-x\|^{2}$, we have

$$
2\langle z-T x, T x-x\rangle+\|T x-x\|^{2}=\|z-x\|^{2}-\|z-T x\|^{2},
$$

and hence

$$
\limsup _{k \rightarrow \infty}\left\|x_{n_{k}}-x\right\|^{2}=\limsup _{k \rightarrow \infty}\left\|x_{n_{k}}-T x\right\|^{2}+\|z-x\|^{2}-\|z-T x\|^{2} .
$$

From $(4.5)$ ), it follows that

$$
\begin{aligned}
\limsup _{k \rightarrow \infty}\left\|x_{n_{k}}-T x\right\|^{2} & \leq \limsup _{k \rightarrow \infty}\left\|x_{n_{k}}-x\right\|^{2} \\
& =\limsup _{k \rightarrow \infty}\left\|x_{n_{k}}-T x\right\|^{2}+\|z-x\|^{2}-\|z-T x\|^{2},
\end{aligned}
$$


and so

$$
\|z-T x\| \leq\|z-x\| \text { for all } x \in K
$$

That is, $z \in A(T)$.

Now we prove $\left\{x_{n}\right\}$ converges weakly to $z$. Suppose not, then there exists another subsequence $\left\{x_{n_{i}}\right\}$ of $\left\{x_{n}\right\}$ which weakly converges to some $y \neq z$. Again in the same way, we have $y \in A(T)$.

From (4.3) ), it follows that both $\lim _{n \rightarrow \infty}\left\|x_{n}-z\right\|$ and $\lim _{n \rightarrow \infty}\left\|x_{n}-y\right\|$ exist. By the elementary properties in Hilbert space, we easily obtain

$$
\begin{aligned}
\lim _{n \rightarrow \infty}\left\|x_{n}-z\right\|^{2} & =\lim _{k \rightarrow \infty}\left\|x_{n_{k}}-z\right\|^{2} \\
& =\lim _{k \rightarrow \infty}\left(\left\|x_{n_{k}}-y\right\|^{2}+2\left\langle x_{n_{k}}-y, y-z\right\rangle+\|y-z\|^{2}\right) \\
& =\lim _{k \rightarrow \infty}\left\|x_{n_{k}}-y\right\|^{2}+2\langle z-y, y-z\rangle+\|y-z\|^{2} \\
& =\lim _{k \rightarrow \infty}\left\|x_{n_{k}}-y\right\|^{2}-\|y-z\|^{2} \\
& =\lim _{n \rightarrow \infty}\left\|x_{n}-y\right\|^{2}-\|y-z\|^{2} \\
& =\lim _{i \rightarrow \infty}\left\|x_{n_{i}}-y\right\|^{2}-\|y-z\|^{2} \\
& =\lim _{i \rightarrow \infty}\left(\left\|x_{n_{i}}-z\right\|^{2}+2\left\langle x_{n_{i}}-z, z-y\right\rangle+\|z-y\|^{2}\right)-\|y-z\|^{2} \\
& =\lim _{i \rightarrow \infty}\left\|x_{n_{i}}-z\right\|^{2}-2\|z-y\|^{2} \\
& =\lim _{n \rightarrow \infty}\left\|x_{n}-z\right\|^{2}-2\|z-y\|^{2}
\end{aligned}
$$

which implies $z=y$, a contradiction. Thus, $\left\{x_{n}\right\}$ converges weakly to an attractive point $z$ of $T$.

Take $\alpha_{n} \equiv 0$. We also obtained easily the following.

Corollary 4.2. Let $K$ be a nonempty closed and convex subset of a Hilbert space $H$ and let $T: K \rightarrow K$ be a $(\alpha, \beta)$-generalized hybrid mapping with $A(T) \neq \emptyset$. Suppose that the sequence $\left\{x_{n}\right\}$ is defined by the following iteration

$$
x_{n+1}=T\left(\beta_{n} x_{n}+\left(1-\beta_{n}\right) T x_{n}\right)
$$

where the sequence $\left\{\beta_{n}\right\}$ in $(0,1)$ such that

$$
\liminf _{n \rightarrow \infty} \beta_{n}\left(1-\beta_{n}\right)>0 .
$$

Then the sequence $\left\{x_{n}\right\}$ converges weakly to an attractive point $z$ of $T$.

\section{References}

[1] J. B. Baillon, Un théorème de type ergodique pour les contractions non linéars dans un espaces de Hilbert, C.R. Acad. Sci. Paris Ser. A-B, 280 (1975), 1511-1541. 1]

[2] R. E. Bruck, A simple proof of the mean ergodic theorem for nonlinear contractions in Banach spaces, Israel J. Math., 32 (1979), 107-116. 1

[3] R. E. Bruck, On the convex approximation property and the asymptotic behavior of nonlinear contractions in Banach spaces, Israel J. Math., 38 (1981), 304-314. 1]

[4] M. Hojo, W. Takahashi, Weak and strong convergence theorems for generalized hybrid mappings in Hilbert spaces, Sci. Math. Jpn., 73 (2011), 31-40. 1

[5] P. Kocourek, W. Takahashi, J. C. Yao, Fixed point theorems and weak convergence theorems for generalized hybrid mappings in Hilbert spaces, Taiwanese J. Math., 14 (2010), 2497-2511. 1. 1, 1 .

[6] F. Kohsaka, W. Takahashi, Fixed point theorems for a class of nonlinear mappings related to maximal monotone operators in Banach spaces, Arch. Math. (Basel), 91 (2008), 166-177. 1

[7] W. R. Mann, Mean value methods in iteration, Proc. Amer. Math. Soc., 4 (1953) 506-510. 1

[8] W. V. Petryshyn, Construction of fixed points of demicompact mappings in Hilbert space, J. Math. Anal. Appl., 14 (1966), 276-284. 3 
[9] H. F. Senter, W. G. Dotson, Approximating fixed points of nonexpansive mappings, Proc. Amer. Math. Soc., 44 (1974), 375-380 3

[10] W. Takahashi, Fixed point theorems for new nonlinear mappings in a Hilbert space, J. Nonlinear Convex Anal., 11 (2010), 79-88. 1. 1

[11] W. Takahashi, J. C. Yao, Fixed point theorems and ergodic theorems for nonlinear mappings in Hilbert spaces, Taiwanese J. Math., 15 (2011), 457-472. 1. 1

[12] W. Takahashi, Y. Takeuchi, Nonlinear ergodic theorem without convexity for generalized hybrid mappings in a Hilbert space, J. Nonlinear Convex Anal., 12 (2011), 399-406. 11, 1 , 2

[13] H. K. Xu, Inequality in Banach spaces with applications, Nonlinear Anal., 16 (1991) 1127-1138. 